\title{
Endoscopic Treatment of Insertional Achilles Tendinopathy
}

\author{
Ali EIGioshy, Emad Zayed, Mohamed Mostafa
}

Department of Orthopedic Surgery, Faculty of Medicine, Al-Azhar University, Cairo, Egypt

Corresponding author: Mohamed Mostafa,email: mohamedelkady.ortho88@gmail.com

\section{ABSTRACT}

Purpose: The purpose of this study was to evaluate the outcome of endoscopic treatment of insertional Achilles tendinopathy. Patient and Methods: This prospective study was held on 15 patients suffered from insertional achilles tendinopathy at Alazhar University Hospitals. There were 7 males and 8 females with mean age 46.27 years (28 to 60 years). Clinical examination, lateral weightbearing Xray of ankle and MRI of ankle were done for all patients. All patients were evaluated preoperatively and postoperatively by AOFAS hindfoot scale with mean follow up 6 months.

Results: The Mean Preoperative AOFAS hindfoot scale of 15 patients in this study was 58.2 (36 to 80) and mean postoperative AOFAS hindfoot scale after 6 months follow up was 86.53 (67 to 97) with P value (.001). There were 3 patients with postoperative scar tenderness. There was neither sural nerve injury nor achilles tendon rupture during follow up period. Conclusion: Endoscopic treatment of insertional achilles tendinopathy had a lot of advantages as being safe and efficient procedure with small incision and cosmetic scar. This technique also could avoid catastrophic complications of open procedures in the form of wound dehiscence, ugly scar and affection of Achilles tendon insertion.

Keyword: Insertional Achilles tendinopathy, Haglund syndrome, endoscopic treatment, sural nerve.

\section{INTRODUCTION}

Achilles tendinopathy is a disorder of hindfoot which occurs frequently in both the active and non-active population. There are two types of Achilles tendinopathy which are insertional and non-insertional Achilles tendinopathy ${ }^{(1)}$. Insertinal Achilles tendinopathy accounted for $20 \%$ to $25 \%$ of total disorders related to Achilles tendon $^{(2)}$.

The location of pathology is the insertion of Achilles tendon and is usually associated with formation of calcifications and bone spurs of Achilles tendon. Insertional Achilles tendinopathy has been defined as a clinical syndrome consisting of swelling, pain and function impairment ${ }^{(3)}$. Symptoms of Haglund deformity, retrocalcaneal bursitis and retrocalcaneal exostosis could be reflective of insertional Achilles tendinopathy ${ }^{(4)}$. Clinically, tenderness has been located at the distal $2 \mathrm{~cm}$ Achilles tendon, and the Haglund deformity could be prominently felt at the superior aspect of the posterolateral calcaneal tuberosity ${ }^{(5)}$.

Lateral weightbearing xray is done to assess posterior calcaneal angle (fowler and Philip angle) ${ }^{(6)}$ and MRI for assessment of integrity or degeneration of achilles tendon and retrocalcaneal bursitis ${ }^{(7)}$.

Non-operative modalities of treatment are rest, ice packs, NSAIDS, heel lifts ${ }^{(8,9)}$, physiotherapy ${ }^{(10)}$, extracorporal shock wave therapy ${ }^{(11)}$, local platelet rich plasma injection ${ }^{(12)}$ and low level laser therapy ${ }^{(13)}$.

Operative treatment is recommended after failure of conservative treatment for 6 months in the form of open surgery ${ }^{(14)}$ and minimally invasive endoscopic treatment (15). This article presents 15 patients with insertional Achilles tendinopathy after failure of conservative measures for more than 6 months treated with endoscopic removal of thickened synovium,inflamed bursa, resection of postero-superior part of calcaneus (Haglund deformity) and debridment of diseased fibers of Achilles tendon. The purpose of this study was to evaluate the clinical and functional results of endoscopic treatment of insertional Achilles tendinopathy.

\section{PATIENT AND METHODS}

This prospective study has been approved by the Ethical Committee of Al-Azhar University. A total of 15 patients with insertional Achilles tendinopathy were treated in Al-Azhar University Hospitals using endoscopy. All patients had signed an informative consent form. We included Patients with insertional Achilles tendonopathy with failed conservative treatment for more than 6 months.

Exclusion criteria were: a) Previous surgery to calceneus or Achilles tendon., b) Achilles tendon rupture, c) Vascular insufficiency (impalpable posterior tibial or dorsalis pedis pulse), d) Patients less than 18 years old and e) Insertional Achilles tendinopathy with more than $50 \%$ affection of tendon circumference.

There were 8 females and 7 males with mean age 46.27years (28 to 60years) with standard deviation 9.17 and there were 3 diabetic patients. 3 patients out of them were smokers while 2 patient had previous local platelet rich plasma injection. The mean body math index (BMI) of patients in our study was 28.92 (19.59 to 35.05) with standard deviation 4.76 . All patients had preoperative clinical assessment in the form of general, local examination and special tests as two finger squeeze test and Thompson test (Fig.1) . Lateral weightbearing xray of ankle was done for all patients pre-operatively to asses haglund deformity by posterior calcaneal angle (fowler and Philip angle) and parallel pitch lines (Fig.2).

MRI was done as routine pre-operative investigation to assess the integrity of Achilles tendon, retrocalcaneal bursitis and Achilles tendon degeneration (Fig.3) . By lateral wightbearing Xray and MRI there were 2 patients $(13.3 \%)$ have retrocalcaneal bursitis only, 3 patients (20\%) have (Haglund deformity, retrocalcaneal bursitis and retrocalcaneal exostosis) and 10 patients $(66.7 \%)$ have Haglund deformity deformity, retrocalcaneal bursitis. All patients were assessed pre-operatively by AOFAS hindfoot scale ${ }^{(16)}$. 
Fig.1

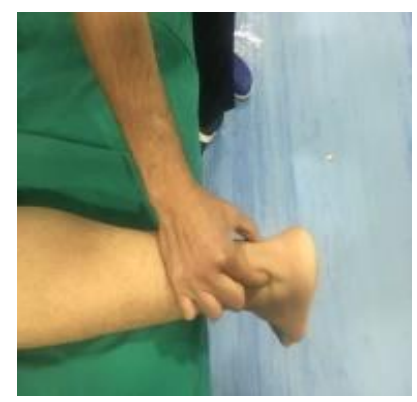

Fig.1a.Two finger squeeze

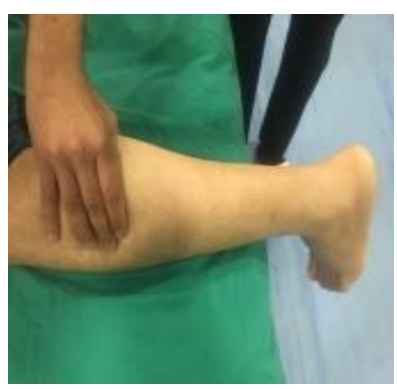

1b.Thompson test.

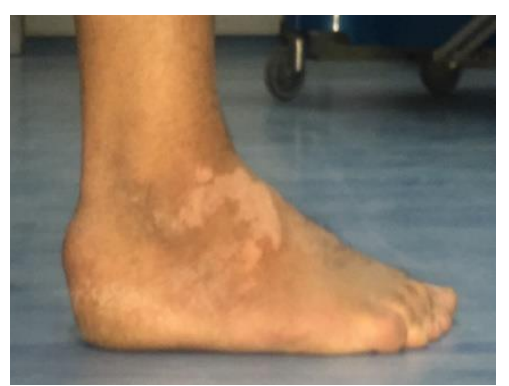

Fig.1c.Haglund deformity

test.

Fig.2

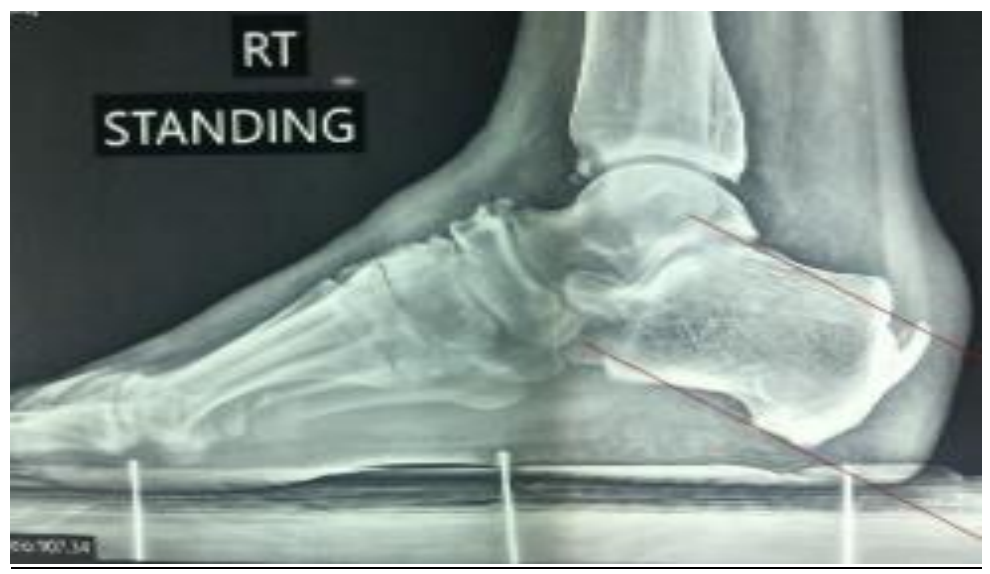

Fig.2a Lateral xray of ankle showing parallel pitch lines.

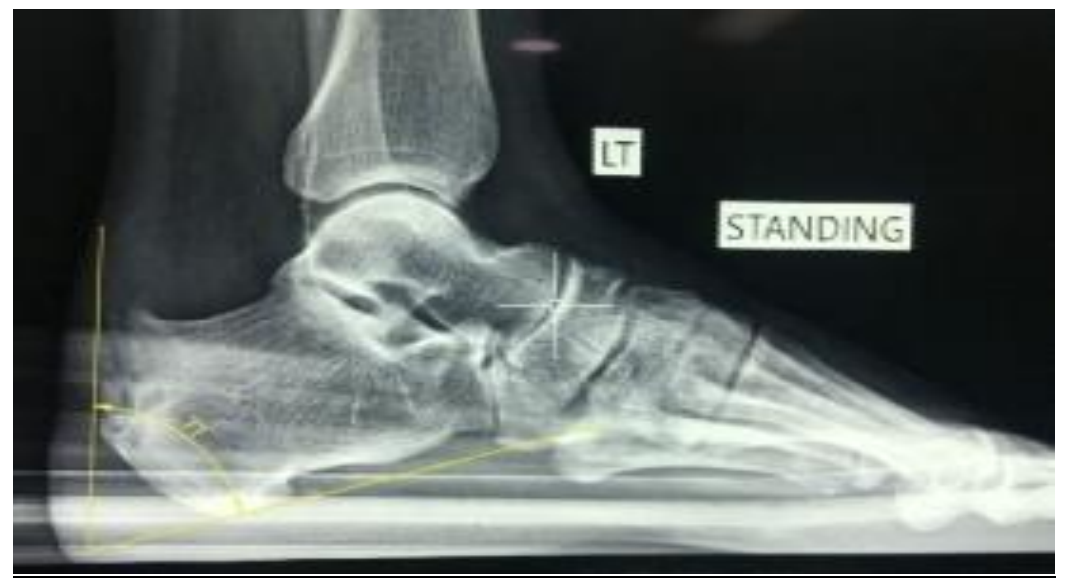

Fig.2b Lateral xray of ankle showing posterior calcaneal angle.

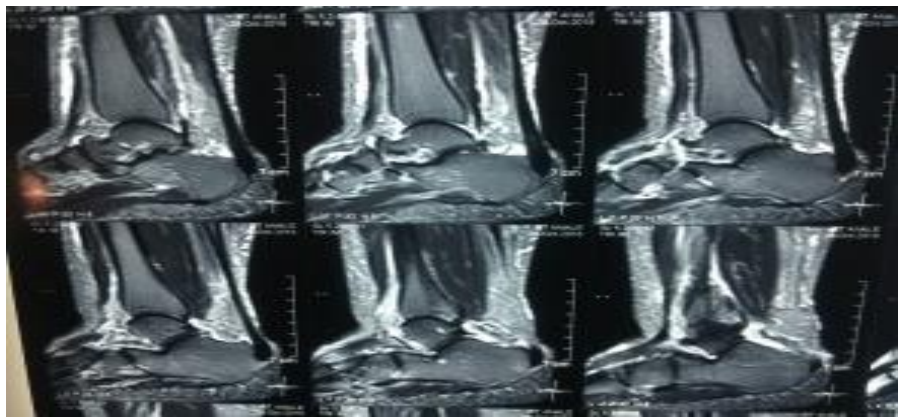

Fig.3 MRI ankle showing.retrocalcaneal bursitis. 


\section{Operative technique}

The operation was performed while the patient prone and under spinal anesthesia. A thigh tourniquet has been inflated after Esmarch ischemia. The position of the foot was at the edge of the operating table. This has enabled us to control ankle dorsiflexion and plantarflexion during the operation. The posterolateral portal was located 1.2 to $2.5 \mathrm{~cm}$ proximal to the tip of the lateral malleolus adjacent to the lateral border of the Achilles tendon (Fig.4a).Vertical stab incision about $0.5 \mathrm{~cm}$ was done, the subcutaneous layer has been splitted usually by a straight mosquito clamp. This incision was just lateral to the Achilles tendon to avoid sural nerve injury. The retrocalcaneal space has been entered with a blunt trocar (Fig.4b). An arthroscope $(4.0 \mathrm{~mm})$ was then placed into the retrocalcaneal space. A posteromedial portal has been done at the level of the tip of the medial malleolus just anterior to the Achilles tendon (Fig.4c).A 4.0-mm arthroscopic shaver was introduced into the medial portal, and the inflamed bursae and thickened synovium were removed $($ Fig.4d). Once working space had been created there was access to the posterior calcaneus and Achilles tendon attachment. Depending on the quality of the bone, either the arthroscopic shaver or a $4.0 \mathrm{~mm}$ arthroscopic burr or both were used to resect the posterosuperior calcaneal prominence (Fig.4e).

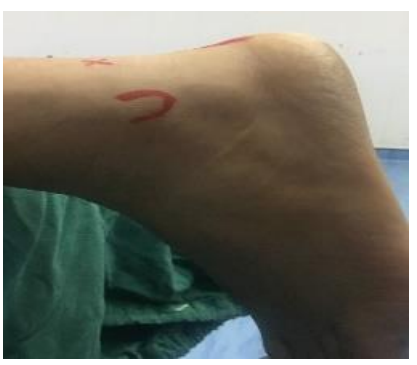

Fig.4a.Posterolateral portal.

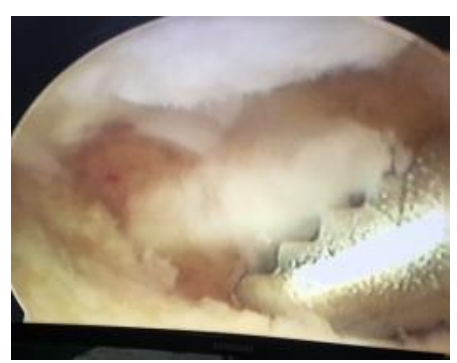

Fig.4d.Shaver in retrocalcaneal space.

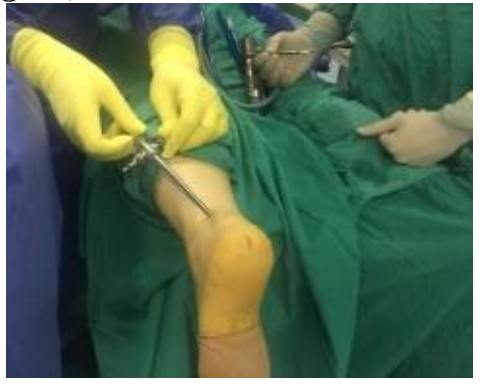

Fig.4b.Posterolateral portal entry with blunt trocar.

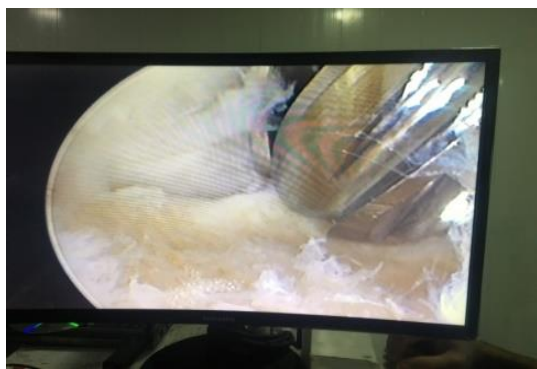

Fig.4e.Arthroscopic burr removing Haglund deformity.

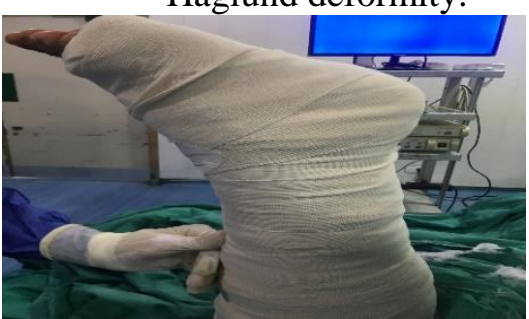

The hooded portions of the instruments were kept toward the tendon to protect the tendon. Bone resection was done systematically usually from a posterior to anterior direction. The resection was carried out both medially and laterally into the sulcus of the calcaneus and down to the attachment of the Achilles tendon. Adequate exposure and resection of the osseous prominence were generally possible with visible and tactile guidance. C-arm was used to determine and document the extent of the resection fluoroscopically (Fig.4f).

Damaged or diseased Achilles tendon was selectively exposed, identified, and removed with the arthroscopic shaver. In some cases an 18-gauge needle was inserted several times into the tendon. The rationale for this technique was to initiate a vascular response within the tendon for healing and was performed after debridement. An arthroscopic probe was inserted into the retrocalcaneal space to confirm attachment of the Achilles tendon. The foot was then hyperplantarflexed and dorsiflexed to verify any last areas of impingement.The retrocalcaneal space was irrigated and suctioned to remove any loose tissue. The portal sites were closedwith two skin mattress sutures. A compressive dressing was applied, and the foot was splinted in slight equinus (Fig.2g). 


\section{Postoperative care and follow up}

Post-operative below knee splint in equinus was done for 2 weeks and post-operative xray was done for all patients (Fig.5).Patients started wightbearing after 2 weeks and returned to work and daily activities after 4 to 6 weeks.

American Orthopedic Foot and Ankle hindfoot scale (AOFAS) has been used for functional evaluation at 6 months.

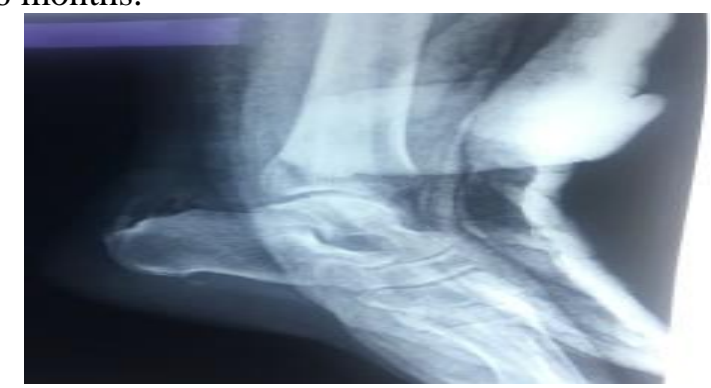

\section{Statistical methods}

Data have been coded and entered using the statistical package SPSS (Statistical Package for the Social Sciences) version 25.

For comparison of serial measurements within each patient the non-parametric Wilcoxon signed rank test has been used (Chan, 2003) ${ }^{(17)}$.

$\mathrm{P}$-values less than 0.05 were considered as statistically significant.

\section{RESULTS}

The mean Pre-operative AOFAS hindfoot scale was 58.2 (36 to 80 ) and mean post-operative AOFAS hindfoot scale after 6 months was 86.53 (67 to 97) with $\mathrm{P}$ value was.001 which showed significant improvement (Table 1 ) (Fig.6).

Fig.5.Postoperative lateral xray of ankle.

Table (1): Pre-Operative and Post- Operative AOFAS hindfoot scale.

\begin{tabular}{|c|c|c|c|c|c|c|}
\hline & Mean & Standard Deviation & Median & Minimum & Maximum & P value \\
\hline $\begin{array}{c}\text { AOFAS score } \\
\text { pre }\end{array}$ & 58.20 & 13.47 & 60.00 & 36.00 & 80.00 & \\
\hline $\begin{array}{c}\text { AOFAS score } \\
\text { post }\end{array}$ & 86.53 & 11.49 & 93.00 & 67.00 & 97.00 & 0.001 \\
\hline
\end{tabular}

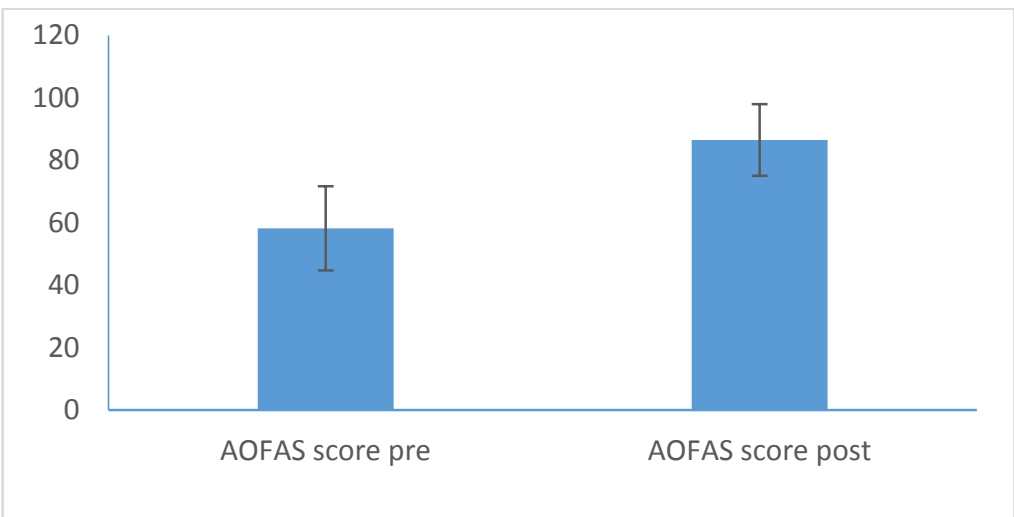

Fig. (6): Bar chart showing AOFAS score in pre-operative and 6 months post-operative patients.

Assessment of pain using AOFAS hindfoot scale in our study showed that pre-operatively we had 2 patients with mild (occasional) pain,9 patients with moderate (daily) pain and 4 patients with severe (almost present) pain.Postoperatively we had 9 patients with no pain, 2 patients with mild (ocassional) pain and 4 patients with moderate (daily) pain with $\mathrm{P}$ value.001 which showed significant improvement (Table 2) (Fig.7).

Table (2): Pain Assessment.

\begin{tabular}{|c|c|c|c|c|c|c|c|c|c|}
\hline & \multicolumn{2}{|c|}{ None } & \multicolumn{2}{|c|}{$\begin{array}{c}\text { Mild } \\
\text { (occasional) }\end{array}$} & \multicolumn{2}{|c|}{$\begin{array}{l}\text { Moderate } \\
\text { (daily) }\end{array}$} & \multicolumn{2}{|c|}{$\begin{array}{c}\text { Severe } \\
\text { (almost present) }\end{array}$} & \multirow{2}{*}{$P$ value } \\
\hline & Count & $\begin{array}{l}\text { Row } \\
\text { N \% }\end{array}$ & Count & $\begin{array}{l}\text { Row } \\
\text { N \% }\end{array}$ & Count & $\begin{array}{l}\text { Row } \\
\text { N \% }\end{array}$ & Count & $\begin{array}{l}\text { Row } \\
\text { N \% }\end{array}$ & \\
\hline $\begin{array}{c}\text { Pain } \\
\text { (preoperative) }\end{array}$ & 0 & $0.0 \%$ & 2 & $13.3 \%$ & 9 & $60.0 \%$ & 4 & $26.7 \%$ & \multirow{2}{*}{0.001} \\
\hline $\begin{array}{c}\text { Pain } \\
\text { (postoperative) }\end{array}$ & 9 & $60.0 \%$ & 2 & $13.3 \%$ & 4 & $26.7 \%$ & 0 & $0.0 \%$ & \\
\hline
\end{tabular}




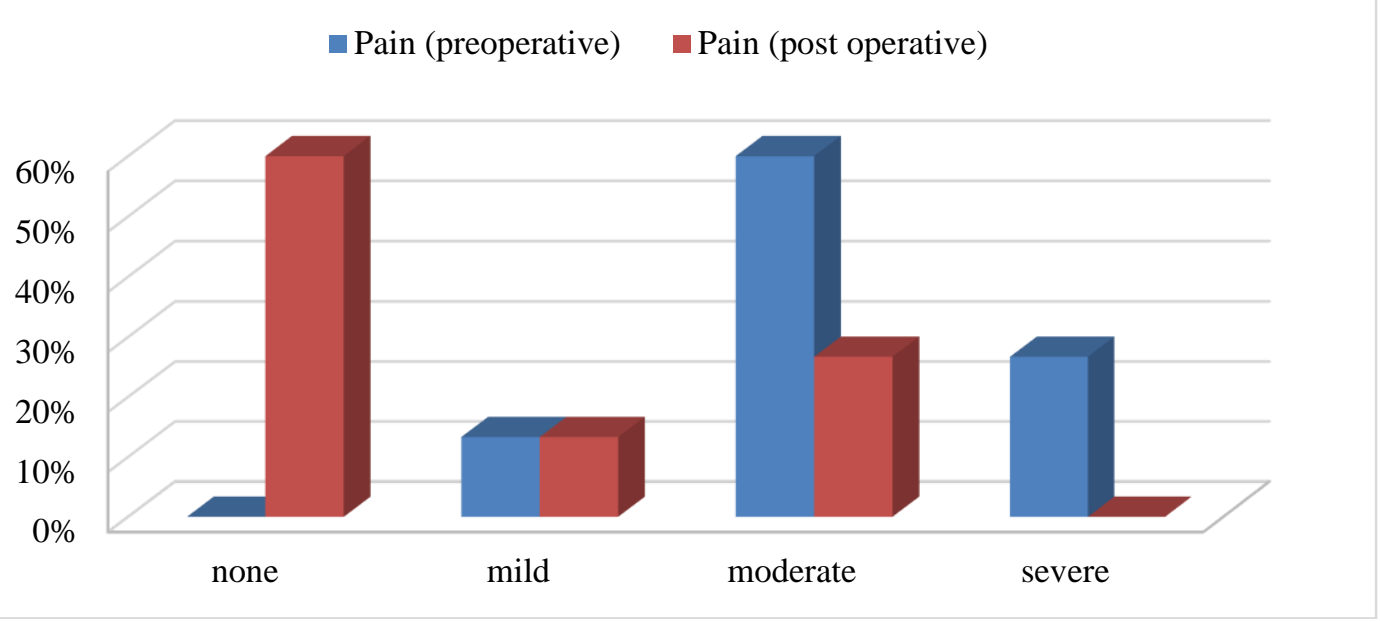

Fig. (7): Bar chart showing comparison of pain in patients pre-operative and 6 months postoperative.

Assessment of activity limitations using AOFAS hindfoot scale in our study showed that pre-operatively we had 6 patients with limitation of recreational activities and 9 patients with limitation of daily and recreational activities. Postoperatively we had 8 patients with no limitation of activities, 5 patients with limitation of recreational activities and 2 patients with limitation of daily and recreational activities with $\mathrm{P}$ value.002 which showed significant improvement (Table 3) (Fig.8).

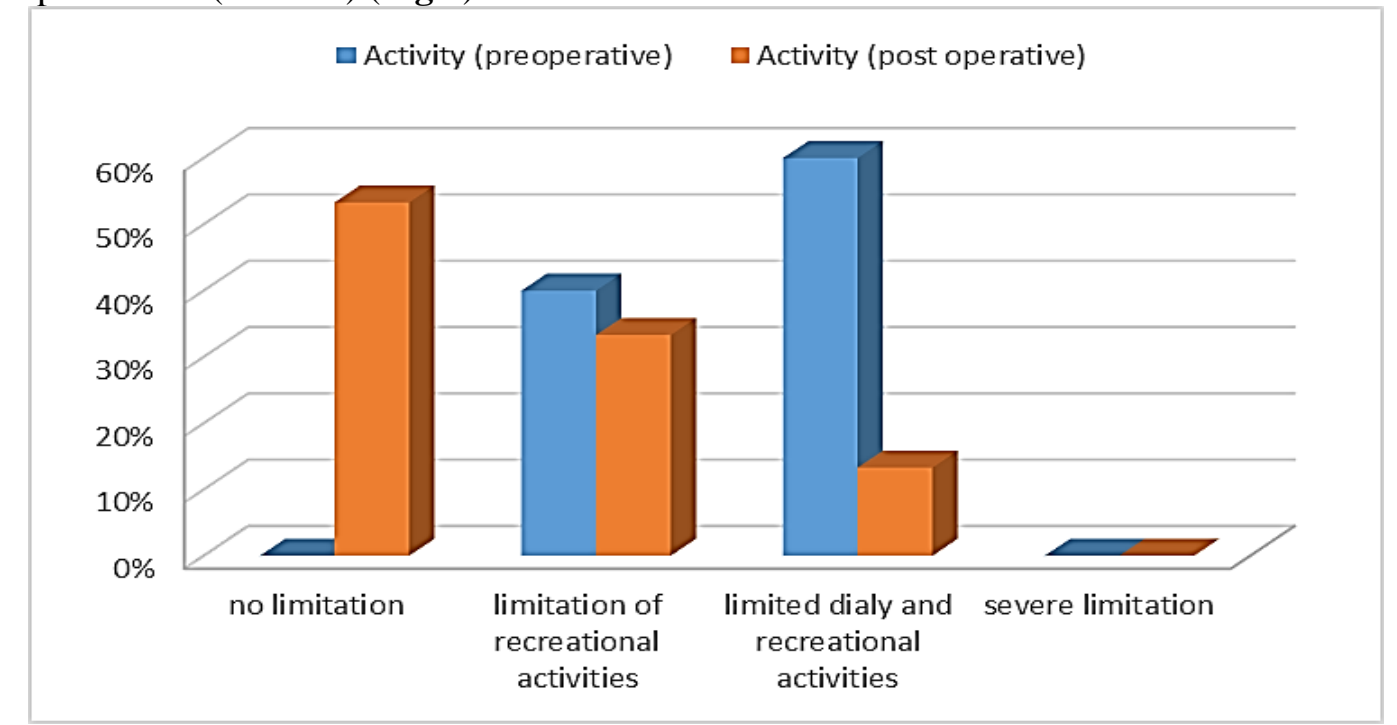

Fig. (8): Bar chart showing comparison of activity limitations in patients preoperatively and 6 months postoperatively

Table (3): Activity limitations pre-operatively and 6 months post-operatively.

\begin{tabular}{|c|c|c|c|c|c|c|c|c|c|}
\hline & \multicolumn{2}{|c|}{ No limitations } & \multicolumn{2}{|c|}{$\begin{array}{l}\text { Limitation of } \\
\text { recreational } \\
\text { activities }\end{array}$} & \multicolumn{2}{|c|}{$\begin{array}{l}\text { Limited daily and } \\
\text { recreational } \\
\text { activities }\end{array}$} & \multicolumn{2}{|c|}{$\begin{array}{l}\text { evere limitation of } \\
\text { daily and } \\
\text { recreational } \\
\text { activities }\end{array}$} & \multirow[t]{2}{*}{$P$ value } \\
\hline & Count & $\begin{array}{l}\text { Row } \\
\text { N \% }\end{array}$ & Count & $\begin{array}{c}\text { Row N } \\
\%\end{array}$ & Count & $\begin{array}{l}\text { Row } \\
\text { N \% }\end{array}$ & Count & $\begin{array}{l}\text { Row } \\
\text { N \% }\end{array}$ & \\
\hline $\begin{array}{c}\text { Activity } \\
\text { (preoperative) }\end{array}$ & 0 & $0.0 \%$ & 6 & $40.0 \%$ & 9 & $60.0 \%$ & 0 & $0.0 \%$ & \multirow{2}{*}{0.002} \\
\hline $\begin{array}{c}\text { Activity (post } \\
\text { operative) }\end{array}$ & 8 & $53.3 \%$ & 5 & $33.3 \%$ & 2 & $13.3 \%$ & 0 & $0.0 \%$ & \\
\hline
\end{tabular}

The mean total function of patients in our study preoperatively was 33.27 (28-40) and postoperatively was 43.13 (38-47) with $\mathrm{P}$ value.001 which showed significant improvement in total function of patients(Table 4) (Fig.9) 
Table (4): Total function in pre-operative and post-operative patients.

\begin{tabular}{|l|c|c|c|c|c|c|}
\hline & Mean & $\begin{array}{c}\text { Standard } \\
\text { Deviation }\end{array}$ & Median & Minimum & Maximum & P value \\
\hline Total function (preoperative) & 33.27 & 4.32 & 32.00 & 28.00 & 40.00 & \multirow{2}{*}{0.001} \\
\hline Total function (post operative) & 43.13 & 3.20 & 44.00 & 38.00 & 47.00 & \\
\hline
\end{tabular}

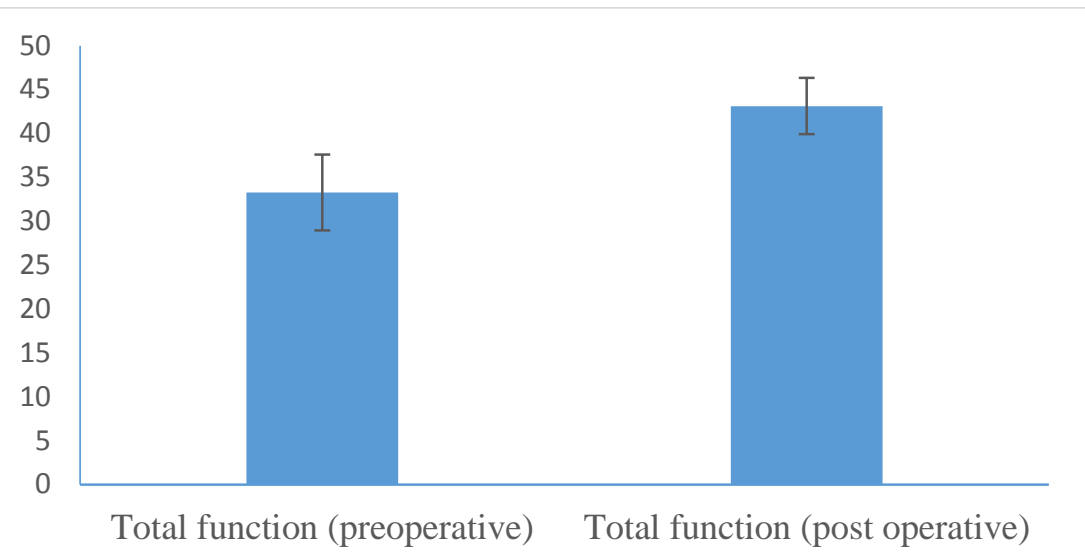

Fig. (9): Bar chart showing comparison of total function in patients pre-operative and 6 months postoperative.

All patients showed clinical and functional improvement according to AOFAS hindfoot scale. Postoperative xray showed sufficient removal of bony prominence in cases of haglund deformity and removal retrocalcaneal exostosis. There were 3 patients with postoperative complications in the form of scar tenderness. There was neither achilles tendon rupture, sural nerve injury nor deep venous thrombosis in our study.

\section{DISCUSSION}

In our study we had 15 patients with endoscopic treatment of insertional achilles tendinopathy with mean Pre-operative AOFAS hindfoot scale was 58.2 (36-80) and mean postoperative AOFAS hindfoot scale after 6 months was 86.53 (67-97) with $\mathrm{P}$ value.001 which showed significant improvement.

In our study there were two cases showed non improvement of pain and function postoperatively which maybe due to high BMI (35.05 and 33.44), they were have triple pathology in the form of ( haglund deformity,retrocalcaneal bursitis and retrocalcaneal exostosis) and more Achilles tendon degeneration.

There were no postoperative complications in the form of deep venous thrombosis, sural nerve injury, Achilles tendon rupture and wound infection but only 3 cases have postoperative scar tenderness.

Ortmann and McBryd ${ }^{(18)}$ has reported on 28 patients (30 heels) with an average follow-up of 35 months with AOFAS hindfoot scale has improved from 62 preoperatively to 92 postoperatively. No wound complications or postoperative infections have been noted, but only one patient has residual pain and swelling posto-peratively and has required an open procedure.Acute Achilles tendon rupture after 19 days of endoscopic decompression has been occurred only in one patient.

Leitze et al. ${ }^{(19)}$ has reported in his prospective cohort study in which 33 patients with endoscopic decompression of the retrocalcaneal space and have been compared to 14 patients who had an open procedure. In comparison with group of patients who had an open procedure, patients in the endoscopic group have greater AOFAS scores and less complications, included infection, altered sensation, and scar tenderness. Limitation of the endoscopic approach was that it couldnot be possible to remove the bone spur entirely or all diseased tissue in patients who had full-thickness intratendinous calcifications.

Complete avulsion after endoscopic calcaneoplasty had not been reported. Although Achilles tendon avulsions after open resection of a Haglund spur had been described in the literature. The reason for this could be that, with endoscopic method, the surgeon can protect the medial and lateral fibers of the Achilles tendon insertion, while during the open resection these fibers had been released ${ }^{(19)}$.

A recent retrospective case series by Ettinger et al. ${ }^{(20)}$ found that patients with insertional achilles tendinopathy who have been treated with double-row fixation anchors have showed significantly more postoperative AOFAS scores in comparison with single-row anchors (79.6 vs 90.2, $\mathrm{P}<0.05$ ). The consistently good postoperative outcomes, despite variations in approach and techniques of reattachment 
Ali ElGioshy et al.

supported the operative treatment for insertional Achilles tendinopathy ${ }^{(20)}$. Patient satisfaction and function, for operative debridement are positive in general. Postoperative AOFAS ankle-hindfoot scores ranged from 81 to 96 and patient satisfaction is more than 87 percent. The serious complications of open surgery are superficial would infection, scar abnormalities, sural neuritis, avulsion of Achilles tendon, recurrence of pain, and DVT ${ }^{(21)}$.

\section{CONCLUSION}

Endoscopic technique for treatment of insertional achilles tendinopathy is usually safe and efficient with the advantage of small incisions with better cosmetic scar, early wightbearing which decrease the risk of deep venous thrombosis, less risk to Achilles tendon rupture, and also less wound complications such as dehiscence, painful or ugly scars, nerve entrapment within the scar and hypoesthesia.

\section{REFERENCES}

1. Van Dijk CN, van Sterkenburg MN, Wiegerinck JI, Karlsson J, Maffulli N (2011): Terminology for Achilles tendon related disorders. Knee SurgSports Traumatol Arthrosc., 19(5): 835-841.

2. Maffulli N, Sharma P, Luscombe KL (2004): Achilles tendinopathy:aetiology and management. J R Soc Med., 10: 472-476.

3. Miao XD, Jiang H, Wu YP, Tao HM, Yang DS, Hu H (2016): Treatment of Calcified Insertional Achilles Tendinopathy by the Posterior Midline Approach. J Foot Ankle Surg., 55(3):529-534.

4. Watson A, Anderson R, Davis W (2000): Comparison of results of retrocalcaneal decom-pression for retrocalcaneal bursitis and insertional Achilles tendinosis with calcific spur. Foot Ankle Int.,21(8):638642.

5. Paavola M, Kannus $P$, Järvinen TA, Khan K, Józsa L, Järvinen M (2002): Achillestendinopathy. J Bone Joint Surg Am.,84(11):2062-76.

6. Tourné Y, Baray AL, Barthélémy $\mathbf{R}$, Moroney $\mathbf{P}$ (2018): Contribution of a new radiologic calcaneal measurement to the treatment decision tree in Haglund syndrome. Orthop Traumatol Surg Res.,104(8):12151219.

7. Nicholson CW, Berlet GC, Lee TH (2007): Prediction of the success of nonoperative treatment of insertional Achilles tendinosis based on MRI. Foot Ankle Int.,28(4):472-477.

8. De Jonge S, Tol JL, Weir A, Waarsing JH, Verhaar JA, de Vos RJ(2015): The Tendon Structure Returns to
Asymptomatic Values in Nonoperatively Treated AchillesTendinopathy but Is Not Associated With Symptoms: A Prospective Study. Am JSports Med.,43(12):2950-8.

9. Shaikh Z, Perry M, Morrissey D, Ahmad M, Del Buono A, Maffulli N(2012): Achilles tendinopathy in club runners. Int J Sports Med.,33(5):390-4.

10.Jonsson P, Alfredson H, Sunding K, Fahlstrom M, Cook J (2008): New regimen for eccentric calf-muscle training in patients with chronic insertional Achilles tendinopathy: results of a pilot study. $\mathrm{Br} \mathrm{J}$ Sports Med.,42(9):746-749.

11.Waugh C,Morrissey D,Jones Eet al.(2015):Invivo biological response to extracorporeal shock wave therapy in human tendinopathy.EuropeanCells and Materials, 29: 268-280.

12.Zhou Y, Wang J (2016): PRP Treatment Efficacy for Tendinopathy: A Review of Basic Science Studies. Biomed Res Int., 1:8.

13. Langer $P$ (2015): Two emerging technologies for Achilles tendinopathy and plantar fasciopathy. Clin Podiatr Med Surg.,32(2):183-193.

14. Yodlowski ML, Scheller AD, Minos L (2002): Surgical treatment of Achilles tendinitis by decompression of the retrocalcaneal bursa and the superior calcaneal tuberosity. Am J Sports Med.,30(3):318-21.

15. Kaynak G, Ogut T, Yontar NS, Botanlioglu H, Can A,Unlu M (2013): Endoscopic calcaneoplasty: 5-Year results. ActaOrthop Traumatol Turc.,47:261-265.

16. Ceccarelli F, Calderazzi F, Pedrazzi G (2014): Is there a relation between AOFAS ankle-hindfoot score and SF36 in evaluation of Achilles ruptures treated by percutaneous technique?. The Journal of Foot and Ankle Surgery, 53(1): 16-21.

17. Chan YH (2003): Biostatistics102: Quantitative Data Parametric \& Non-parametric Tests. Singapore Med J., 44(8): 391-396.

18. Ortmann FW, McBryde AM (2007): Endoscopic bony and soft-tissue decompression of the retrocalcaneal space for the treatment of Haglund's deformity and retrocalcaneal bursitis. Foot Ankle Int.,28(2):149-53.

19. Leitze Z, Sella E, Aversa J (2003): Endoscopic decompression of the retrocalcaneal space. J Bone Joint Surg Am.,85(8):1488-1496

20.Ettinger S, Razzaq $R$, Waizy $H$, Claassen L, Daniilidis K, Stukenborg-Colsman C,Plaass C (2016): Operative Treatment of the Insertional Achilles Tendinopathy Through a Transtendinous Approach. Foot Ankle Int.,37(3):288-93.

21. Lin HA, Chong HA, Yeo W (2014) Calcaneoplasty and reattachment of the Achilles tendon for insertional tendinopathy. J Orthop Surg (Hong Kong),22(1):56-59. 